Article

\title{
The Influence of Leaders' Positive and Implicit Followership Theory of University Scientific Research Teams on Individual Creativity: the Mediating Effect of Individual Self-Cognition and the Moderating Effect of Proactive Personality
}

\author{
Lei Wang ${ }^{1(1)}$ and Xinya Liang ${ }^{2, *}$ (1) \\ 1 College of Economics and Management, Northeast Agricultural University, Harbin 150030, China; \\ wanglei_1980@neau.edu.cn \\ 2 Educational Statistics and Research Methods, College of Education and Health Professions, \\ University of Arkansas, Fayetteville, AR 72701, USA \\ * Correspondence: x1014@uark.edu; Tel.: +1-479-575-7948
}

Received: 1 March 2020; Accepted: 19 March 2020; Published: 23 March 2020

check for updates

\begin{abstract}
Leaders' positive and implicit followership theory (LPIFT) in a university scientific research team influences innovation in university scientific research. Individual creativity is an important aspect of innovation in university scientific research. However, the influence mechanism of LPIFT of a university scientific research team on individual creativity remains unclear. Based on social cognitive theory and the input-process-output (IPO) theoretical model, we selected a postgraduate supervisor and postgraduates of a university scientific research team as the research objects. We explored the influence between LPIFT of a university scientific research team leader and individual creativity using a questionnaire. A total of 413 valid paired samples were collected from the postgraduate and postgraduate supervisor. We drew the following conclusions: LPIFT of the university scientific research team had a direct positive effect on individual creativity. Individual creative role identity, individual creative self-efficacy, and individual willingness to create knowledge had completely mediating effects on the relationship between LPIFT of the university scientific research team and individual creativity. Proactive personality positively moderated the relationship between LPIFT of the university scientific research team and individual creative role identity, as well as LPIFT of the university scientific research team and individual creative self-efficacy. Proactive personality also positively moderated the mediating effect of individual creative role identity and individual creative self-efficacy. However, the moderating effect of proactive personality between LPIFT of university research teams and individual willingness to create knowledge was not significant. Proactive personality also did not positively moderate the mediating effect of individual willingness to create knowledge.
\end{abstract}

Keywords: leaders' positive and implicit followership theory (LPIFT); individual creativity; proactive personality; individual creative role identity; individual creative self-efficacy; individual willingness to create knowledge

\section{Introduction}

Creativity keeps university scientific research alive [1] and is the key driving factor for an organization to achieve and sustain competitive advantages [2]. To further encourage university scientific research teams and talents to have better environments and policies as well as provide relevant 
assistance to complete their work in their field of study, China has issued the Chang Jiang Scholars Program, the National Special Support Program for High-Level Talent, the Innovative Talent Promotion Program, and other policies in the National Mediums, and Long-Term Talent Development Plan Outline. To implement this plan, Chinese universities have also introduced various policies to support the development of university teachers and scientific research teams. Both the states and universities provide sufficient funds, policies, and services to all kinds of talent and university scientific research teams. Although these policies provide an environment conducive to the growth of high-level talent and scientific research teams, the creativity levels of different scientific research teams are different in the same growth environment and in the same level and field of scientific research. Similarly, the level of individual creativity of different team members is different under conditions of growth within the same university scientific research team undertaking the same scientific research project. This problem of creativity difference seriously restricts further promotion of individual creativity of university scientific research teams. Excluding the reality of individual differences, one of the main reasons for the creativity difference problem is team leadership in the same environment and under the same task conditions [3].

The university scientific research team leader is the key role and core figure of the team. An excellent team leader can head the direction of development within a discipline and improve the creation of organizational knowledge. Existing research has proved that the behavior of a leader primarily affects the team's behavior, cognition, and individual motivation to create knowledge and determines the development direction of individuals and organizations [4]. Leadership cognition is the source of leadership [5]. Therefore, positive behaviors of university scientific research team leaders come from positive leadership cognition. For example, De and De [6] suggested that empathy is a critical skill to leadership, and empathy provides a prototype of how leader understanding and support improves follower behaviors, and ultimately creates the premise of effective corporate governance in companies. As teams are faced with increasingly complex and changeable internal and external management environments, more leaders became aware that a team's success depends on the leader's character and behavior and also depends on the team's interactions with the leader. Thus, scholars started to focus on studying the cognition of followers [7,8], namely implicit followership theory (IFT). Sy [9] stated that IFT is a preexisting expectation and hypothesis in an individual's mind about the behaviors and characteristics of followers, and its core is the cognitive structure or schema of followers' prototypes. Therefore, the leaders' positive and implicit followership theory (LPIFT) studied here is the expectation and assumption of leaders on the characteristics and behaviors of effective followers.

IFT is a new theory that reveals the psychological mechanism of leadership, which was developed by western modern management scientists on the basis of social cognition theory [9]. Since the theory was put forward, it has been concerned and recognized by scholars at home and abroad. However, domestic and foreign scholars have not formed a complete theoretical framework for the study of IFT. Scholars mainly apply IFT to the practice of enterprise management, and their research focuses on the formation and the influence of IFT.

The research on the formation factors of IFT mainly focuses on three aspects: individual factors, environmental factors and cultural factors. The individual factors include gender and age [9], and mood and personality [10]. The second is the environmental factors. The family environment of individual growth [11], the market situation outside the organization and the structural characteristics within the organization [12] have certain influence on the formation and development of follower prototype. The third is the cultural factors. Due to the cultural background differences between China and the west, the public has different understanding of followers [13].

Scholars have also studied the outcome variables of IFT. Whiteley et al. [14] confirmed that LPIFT can improve employees' work performance through their performance expectation, preference, and leader-member exchange (LMX) relationship [14]. Sy [9] shifted the research perspective to the team level and found that LPIFT also significantly improves team performance. In addition, the empirical study has also showed that LPIFT significantly affected organizational commitment and organizational 
citizenship behavior of employees [15]. In addition, some scholars have demonstrated that LPIFT can improve employees' subjective well-being [10] and job satisfaction [9].

At present, studies where scholars have applied implicit theory in the research on individual creativity of university scientific research teams are lacking. However, scholars have also conducted some research in related fields, mainly including the following aspects: First is the implicit theory of creativity and its application in the field of education, which mainly involves teachers' implicit concept of creativity and its influence on cultivating student creativity. For example, Gralewski and Karwowski [16] tested the structure of teachers' implicit creativity theory in high schools in Poland, and they investigated the effect of this implicit creativity theory structure on the accuracy of teachers' evaluation of student creativity. Stanislav [17] proved through empirical research that individualism or collectivism can affect the implicit view of individual creativity, which is helpful for making adjustment in a bilingual education environment to provide better conditions for students to support the development of their creativity. Second is the influence of implicit coordination on team creativity. For example, Zhang [18] empirically investigated the process of the influence of implicit coordination on the creativity of cross-functional teams in enterprises and the moderating effect of task conventionalization and task interdependence on this process. Zhao [19] introduced and explored implicit coordination in the relationship between individual-organization matching and cross-functional team creativity, and they conducted an empirical analysis using insider identity perception as a moderating variable. Third is the study of the relationship between implicit self-esteem and creativity. For example, Fan [20] explored the relationship between implicit self-esteem, explicit self-esteem, and creativity tendency of university students. In terms of external situational factors of individual creativity, leadership has the most direct influence on individual creativity. Research demonstrated the influence of explicit leadership theories on individual creativity such as leadership traits [21], leadership behaviors [22], leadership power [14], and leadership style [23]. For example, Asif et al. [24] conducted a survey with 233 Chinese public sector employees in three stages, and the empirical study found that ethical leadership had a positive impact on individual creativity.

Based on the literature review above, research has mainly focused on the influence mechanism of individual and team creativity in the context of enterprises, whereas few studies have been conducted in the context of Chinese universities. It is worth noting that enterprises and universities are two different types of institutions, and there are considerable differences between them in terms of personnel structure, organizational structure, motivation of knowledge creation, behavior of knowledge creation, achievement of knowledge creation and achievement evaluation [25,26]. Moreover, Newman-Storen [27] proposed that we should create an interface between creativity and leadership theory in dealing with "wicked problems" to ensure the leadership in sustainability. However, the existing literature has not given a clear answer about whether and to what extent the LPIFT of university scientific research team affects individual creativity. This was the first research purpose of this paper.

Regarding the mediating variable of individual creativity, the research mainly considered the psychological path. The psychological path mainly includes three aspects: motivation, cognition, and emotion. Among them, cognition is mainly the cognition of self-creativity, including individual creative role identity, individual creative self-efficacy, and individual willingness to create knowledge. For example, Wang [28] found that employees' identification with creative roles plays a mediating role between transformational leadership and employee creativity. Jaisal [29] found that self-efficacy created by employees plays a mediating role between transformational leadership and employee creativity. Wang [30] also found that employees' innovative willingness plays a partial mediating role between work passion and employees' creativity. Ritcher et al. [31] verified that the positive relation between creative self-efficacy and individual creativity in which team informational resources, comprising of both shared "knowledge of who knows what" and functional background diversity, benefit the creativity of individuals more with higher creative self-efficacy. However, the research path of IFT mainly states that the IFT of leaders influences leaders' cognition or behavior toward their followers, whereas leaders' cognition or behavior toward their followers influences individual, team, 
and organization outcomes. Studies proved that LPIFT can stimulate leaders' positive perception of employees, significantly promote transformational leadership [15] and mentoring behaviors [32] and influence their favor for employees [14] and leader-member exchange relationships [14,15]. Guo [33] validated that the anti-prototype of leaders leads to emotional exhaustion of employees through empirical research on what leads to employee turnover. From the research on the influence of LPIFT on individual job satisfaction, individual emotion, personal performance, and so forth, most research paths investigated the influence of LPIFT on individual outcomes through the influence of a leader's behavior and cognition, but research has seldom explored the path of an individual's psychological cognition. Therefore, from the perspective of individual self-cognition, we examined the mediating effect of individual creative role identity, individual creative self-efficacy, and individual willingness to create knowledge on the LPIFT of a university scientific research team and individual creativity. This was the second aim of this study.

Studies showed that both individual factors and external situational factors influence individual creativity. Within university scientific research teams, team leaders have the same expectations and assumptions about the characteristics and behavioral prototypes of effective followers, but the creativity of different team members is different, which may be caused by individual cognitive differences. Individual cognitive differences are usually related to stable personality traits, and proactive personality is a stable personality trait [34]. Since the concept of proactive personality was introduced, it has aroused widespread interest in the academic field, and its important role in explaining individual behavior is widely recognized by scholars [35]. Individuals with a higher proactive personality actively cope with difficulties, challenges, and constantly changing internal and external environments, improve work skills, have opinions on improving the workflow, etc., in order to achieve their goals. Conversely, individuals with a lower proactive personality are often constrained by the environment and rarely change environments. Sometimes, they will even be changed by the environment, and their ability to identify and grasp good opportunities is poor. In addition, they are not good at taking advantage of opportunities to gain more advantages. Studies demonstrated that a proactive personality can mitigate the negative correlation between perceived overqualification and perceived job autonomy, as well as between perceived overqualification and the initial level of job-related positive effects [36]. Shin andk Eco [37] conducted a survey on leaders and members of 103 Korean work teams to confirm that the team creative efficacy and risk-taking norms affect the team creative performance positively and significantly through team proactive. Tang [38] demonstrated that an employee's proactive personality plays a moderating role between the LMX relationship and employee creativity through empirical studies, as well as between the LMX relationship and insider identity cognition. Through a multilevel analysis, Zhang [39] found that social exchange and social development play a mediating role between a high-performance work system (HPWS) and employee task performance, as well as HPWS and organizational citizenship behavior. Proactive personality was found to attenuate HPWS's direct effect on the ability to thrive and indirect effects on employee task performance and organizational citizenship behaviors (OCBs) through thriving. In addition, existing studies confirmed that a proactive personality has significant, positive effects on entrepreneurial motivation [40], self-efficacy [41], job involvement [42], and job satisfaction [43]. Therefore, the third purpose of this study was to explore the moderating effect of a proactive personality and the moderated mediating effect of individual creative role identity, individual creative self-efficacy, and individual willingness to create knowledge.

To summarize, we took individual creative role identity, individual creative self-efficacy, and individual willingness to create knowledge as mediating variables, and proactive personality as a moderating variable, to build a mediation model to study the mechanism of LPIFT of a university scientific research team on individual creativity. 


\section{Theory and Hypotheses}

\subsection{LPIFT of the University Scientific Research Team and Individual Creativity}

IFT is based on the theory of social cognition, which pays more attention to the cognitive structure of individual followers. According to the cognitive classification model, when the IFT of the leader is activated, the leader will compare it with the explicit followership of the team member to generate a corresponding conceptual cognition of the team member and adopt the corresponding behavioral model according to this cognition [44]. Researchers found that IFT has both positive and negative dimensions [9]. Positive dimensions lead to positive results [14]. When the LPIFT is established and activated, the emergence of various associated concepts is triggered, which induces related behaviors [44]. Zhu [45] stated that the Pygmalion effect provides a theoretical basis for studying the influence mechanism and boundary conditions of IFT. Pygmalion effect theory indicates that teachers' expectations of student performance significantly improve student performance [46]. Scott [47] pointed out that leaders' expectations at work can influence individual creative behaviors. Therefore, we assume that when the real performance of followers is matched with the positive and implicit followership theory prototype of a leadership's mind, leaders will more positively evaluate these members, favor them emotionally, help them with behaviors, support them with rewards, encourage them to better engage in scientific research, and provide a material guarantee for them to produce high-level scientific research results. Thus, we hypothesized the following:

Hypothesis 1 (H1). The LPIFT in a university scientific research team will have a significant positive impact on individual creativity.

\subsection{Mediating Effect from the Individual Self-Cognition Perspective}

\subsubsection{Mediating Effect of Individual Creativity in Role Identity}

The theory of role identification was first proposed by McCall and Simmons in 1978. According to this theory, role identity refers to an individual's understanding and cognition of a specific role of themselves as well as their cognition and evaluation of themselves. Role identity theory is an individual's self-positioning of their role and their desire for others to perceive them [48]. Farmer [49] proposed the concept of creative role identity based on role identity and innovation theories. They thought that creative role identity refers to the importance individuals attach to their innovation ability, subjective feelings, and internal identity. Creative role identity among university scientific research team members incorporates knowledge creation, research, and innovation in their job. In the process of academic research, university scientific research team members clearly know who they are and what they should do, continuously face and solve the problems of complex and difficult research, actively promote knowledge innovation, and constantly produce a high level of scientific research achievements and valuable and meaningful academic ideas. The research also showed that the academic role identity of postgraduates has a significant and positive effect on the generation of scientific research creativity [50]. Wang [51] used the data of 395 supervisors and employees in a Taiwan hotel to verify that creative role identity plays a mediating role between transformational leadership and individual employee creativity.

According to role identity theory and symbolic interaction theory, the expectations from important others in the organization construct the individual role identity and self-image [52]. That is, team members know themselves through the expectations of their leaders or colleagues in the team. Callero [53] proposed that role expectation constructs role identity. Riley [54] argued that leaders' or colleagues' expectations may be the key reference and predictive variable for individual creative role identity. Therefore, through the prototype hypothesis of positive followership in the mind, university scientific research team leaders will continuously effectively and emotionally interact with 
the team members, actively provide them with good scientific research conditions and work support behaviors and make the team members feel the significance of engaging in scientific research. Team members perceive and obtain their own role position among constant scientific research breakthroughs and scientific research innovations, which clarifies their identity and role in the team. In the long run, individual creativity identity is formed. According to role identity theory, the role identity of individuals comes from understanding the identity they assume and the meaning of feedback they receive [28]. Among university scientific research team leaders' expectations of the characteristics and behaviors of effective followers, team members continuously feel scientific research support and emotional motivation from the team leaders. When the leader's perception of the role of team members is highly consistent with the perception of individual members, individuals will constantly adjust their knowledge creation behaviors according to the requirements of the role, thus obtaining a higher recognition for the role of creativity.

To summarize, the expected positive followership prototype of university scientific research team leaders on the role of creativity affects the team members' cognition and evaluation of the role of creativity and forms the role identity of self-creativity. In addition, self-identity of creative roles prompts individuals to continuously think critically, strengthen learning ability, constantly capture the academic frontier, and continuously promote the discovery and generation of new knowledge. Thus, we hypothesized the following:

Hypothesis 2a (H2a). The LPIFT in a university scientific research team has a significant positive effect on individual creative role identity.

Hypothesis $\mathbf{2 b} \mathbf{b} \mathbf{H} \mathbf{2 b})$. The individual creative role identity has a significant positive effect on individual creativity.

Hypothesis 2 (H2). Individual creative role identity plays a mediating role between the LPIFT of a university scientific research team and individual creativity.

\subsubsection{Mediating Effect of Individual Creative Self-Efficacy}

Self-efficacy is the core concept of social cognition theory, which was first proposed by Bandura in 1977. According to this theory, self-efficacy is a belief of individual cognition that mainly reflects an individual's perception and confidence in whether they can successfully complete a specific task or tasks [55] and can affect an individual's judgment, behavioral motivation, and behavioral choice [56]. Self-efficacy theory also holds that individual experience changes their psychology and behavior through self-regulation, and the choice of individual behavior strengthens the continuity of their related behaviors. This theory integrates the cognition and emotion of the subject. Starting from the cognitive factors of the subject, the behavioral motivation of the individual is studied. Tierney [56] combined self-efficacy and innovation to the concept of creative self-efficacy. They thought that creative self-efficacy is a belief or expectation that individuals express to themselves in the process of knowledge creation. Due to the complexity, difficulty, and originality of knowledge creation activities, individuals engaged in this activity must have excellent scientific research accomplishments, master professional and systematic scientific knowledge and advanced and effective scientific methods, and have the confidence and courage to conquer academic difficulties. Creative self-efficacy is a specific form of personal belief in knowledge creation [57]. Members with a strong sense of creative self-efficacy have strong self-confidence. They believe that they can inspire new scientific research and find new problems through their scientific research process, and they firmly believe that they can use advanced scientific research methods to solve problems and obtain innovative results. Studies also show that creative self-efficacy has a significant positive impact on individual creativity in corporation research on development teams [31]. Yao [58] confirmed that the scientific research self-efficacy of postgraduates has a significantly positive impact on postgraduate creativity through empirical tests. 
Bandura [55] thought that the source of self-efficacy mainly includes four aspects-self-efficacy experience, alternative experience, verbal persuasion, and emotion and physiological state. The team leader's shaping of the positive follower prototype makes the team members strive to achieve the characteristics and behaviors of the positive followers to more easily achieve career success. According to the Pygmalion effect, the leader has higher creative expectations for the individuals who match the prototype they positively follow, thus encouraging and supporting them from various aspects [14]. This exemplary effect is also perceived by other team members who gain the experience of substitution. The leaders of university scientific research teams are more likely to establish a relatively close teacher-student relationship by emotionally following the particular liking of the effective individual through the prototype hypothesis of positive followership in mind. When LPIFT is established and activated, the followers feel the expectation and encouragement from the leader. In this process, the positive emotional and physiological information of the followers is gradually awakened and continuously developed toward the prototype of the follower expected by the leader [13].

To summarize, creative self-efficacy often plays a mediating role in the cognitive process of individual creativity [29]. Through the assumption of the positive followership prototype in the mind, the leaders of scientific research teams in universities have more support and encouragement for effective members, which stimulates their sense of creative self-efficacy to improve their creativity level. Thus, we hypothesized the following:

Hypothesis 3a (H3a). The LPIFT in a university scientific research team has a significantly positive effect on individual creative self-efficacy.

Hypothesis $3 \mathbf{b}$ (H3b). Individual creative self-efficacy has a significantly positive effect on individual creativity.

Hypothesis 3 (H3). Individual creative self-efficacy plays a mediating role between the LPIFT of university scientific research teams and individual creativity.

\subsubsection{Mediating Effect of Individual Willingness to Create Knowledge}

Willingness originates from behavioral intention in planned behavior theory, which mainly refers to the subjective inner state of an individual to have a certain behavior, and an individual's actions or attention on the specific path or method to achieve a certain goal or obtain something [59]. Later, by deepening the study, scholars introduced willingness into the study of knowledge creation, forming the concept of knowledge creation willingness. Knowledge creation willingness refers to the motivation of individuals to create knowledge and the intensity of the desire to create knowledge under certain circumstances. To complete specific tasks, people are willing to try and make attempts [60]. According to planned behavior theory, behavioral willingness is the most direct factor influencing behavior [61], whereas willingness comes from the behavioral intention in planned behavioral theory. Therefore, willingness is also the factor most directly influencing behavior. The stronger the willingness of individuals from scientific research teams in universities to engage in knowledge creation, the more positive the attitude toward scientific research activities and the more conducive to the burst of creative thinking, the development of creative activities, and the acquisition of creative fruits. Research results showed that individual innovation behavior is influenced and driven by individual innovation willingness [62], and a significantly positive correlation exists between individual innovation willingness, behavior, and ability [63].

In planned behavior theory, behavioral willingness is influenced by behavioral attitude, subjective norms, and perceived behavioral control. Taylor [64] proposed a deconstructed theoretical model of planned behavior, in which attitude is interpreted to constitute useful cognition, usable cognition, and compatibility. By establishing positive follower prototypes, the leaders of university scientific research teams form their own cognitive structure and emotional response system to the follower prototypes. After matching with the characteristics and behaviors of the real team members, they have different 
likings and trust for the team members. Therefore, team members can feel different levels of support and help from leaders in the process of scientific research activities. As such, we can judge the extent to which LPIFT improves individual work performance, reduces the physical or mental effort, and requires the past experience and the present need to engage in knowledge creation activities. Subjective norms are influenced by groups that have important relationships with the organization, including those from the leadership [64]. The assumptions and expectations of university scientific research team leaders about the characteristics and behaviors of positive followers influence the individual normative beliefs and compliance motivations within subjective norms [61]. Perceptual behavior control is an individual's perception of how difficult it is to autonomously control a certain behavior, which reflects to what extent an individual can guarantee the completion of a certain behavior given their available resources and opportunities [65]. In the process of engaging in scientific research activities, university scientific research team leaders match the performance of actual team members with their ideal follower prototypes. Each team member is assigned different scientific research tasks, according to the matching degree, and is provided with different opportunities for meetings, learning, and training. When team members believe that they have obtained more resources and opportunities, they have a stronger perception of behavioral control in the target task, and their control and completion beliefs are firmer, which is more conducive to completing the target task.

To summarize, the precondition to enhance individual creativity in university scientific research teams is improving members' enthusiasm for knowledge creation. Through the assumption of a positive followership prototype in the mind, the leaders of scientific research teams in universities establish good relationships with team members and provide them with talent, funds, materials, and environmental support to improve the enthusiasm of effective members in scientific research and further enhance their creativity. Thus, we hypothesized the following:

Hypothesis 4a (H4a). LPIFT in a university scientific research team has a significantly positive effect on individual willingness to create knowledge.

Hypothesis $4 \mathbf{b}(\mathbf{H} 4 \mathbf{b})$. The individual willingness to create knowledge has a significantly positive effect on individual creativity.

Hypothesis 4 (H4). Individual willingness to create knowledge plays a mediating role between LPIFT of university scientific research teams and individual creativity.

\subsection{Moderating Effect of a Proactive Personality}

Bateman [66] first proposed the concept of a proactive personality, referring to the tendency of individuals to take the initiative to influence their surrounding environment, which is a relatively stable personality trait. Individuals with a high proactive personality are not constrained by the surrounding environment and actively change unfavorable environments into favorable environments. Individuals with higher proactive personalities can also identify job opportunities well and take a series of proactive behaviors to change the unsatisfactory status quo in reality to achieve the goals of individuals and organizations [67,68]. Morrison [69] proposed that employees with high proactive characteristics are more confident and actively engaged in work. They control the environment with their own series of proactive behaviors and shorten the time for team members to identify with their work role identity. Therefore, members with high initiative on a university scientific research team actively figure out LPIFT of the university scientific research team and strive to meet the requirements of team leaders in terms of knowledge, ability, and quality. For example, they take the initiative to learn new scientific research methods, track forward hot spots, and find innovative points in research, to quickly grasp development trends in their respective discipline, master the mainstream scientific research methods of the discipline, and form their own academic views or research ideas on a research problem. They are motivated to face research problems, not discouraged and not compromised, and they constantly 
correct their attitudes toward research, regulating their own research behavior. Through this series of active behaviors, team members clearly understand their responsibilities, directions, and tasks of research; deeply understand their creative role identity; and generate a sense of creative identity.

Proactive personality, also known as prospective personality by scholars, is a positive psychological quality and represents a trend in positive psychology. Individuals with a high proactive personality do not stick with the status quo, but they actively advocate change, put it into practice, and do not compromise when facing difficulties until the environment changes [67]. Generally, the higher the proactive personality of individual members of scientific research teams in universities, the higher the awareness of responsibility [70]. In the process of daily learning and scientific research training, they strive to keep close to the prototype in the mind of leaders and constantly improve themselves in knowledge, ability, quality, and other aspects, thus becoming followers of university scientific research team leaders. Therefore, when they are looking for scientific innovations or challenging scientific problems, they firmly believe that they can solve all kinds of difficulties encountered in the process of knowledge creation and constantly inspire the confidence of members. As such, they have a strong belief in their knowledge creation ability, and their self-confidence is enhanced, thus significantly increasing their sense of self-efficacy.

As a relatively stable tendency to cause environmental changes, a proactive personality is the central structure for managing and organizing a team or leading individual behaviors in a team [71]. Members with a higher level of proactive personality are more inclined to communicate with the outside world actively and effectively obtain high-quality information to identify opportunities and take effective actions [66]. LPIFT of university scientific research teams clarifies the direction of team members' efforts in knowledge, ability, quality, and other aspects. Members with a higher level of proactive personality actively communicate with team leaders and other members and actively learn, thus discovering opportunities to engage in scientific research such as discovering topics and new methods. Only in this way can the idea of scientific research be realized. The supportive policies and measures provided by the leaders stimulate the willingness of the team members to engage in scientific research. Thus, we hypothesized the following:

Hypothesis 5a (H5a). A proactive personality positively moderates the correlation between LPIFT of university scientific research teams and the individual creative role identity.

Hypothesis $\mathbf{5 b}(\mathbf{H} 5 \mathbf{b})$. A proactive personality positively moderates the correlation between the LPIFT of university scientific research teams and the individual creative self-efficacy.

Hypothesis 5c (H5c). A proactive personality positively moderates the LPIFT of university scientific research teams and the individual willingness to be creative.

\subsection{Moderated Mediation Effect}

Through the above analysis, individuals with a higher proactive personality are found to be less affected and restricted by external factors, and they are more used to actively discovering favorable opportunities for themselves and taking effective action to change their environment. Therefore, in a university scientific research team, individuals with a high proactive personality actively cooperate with the leader's preference for followers. They constantly adjust their own characteristics and behaviors to cater to the leaders, become their effective followers, and win more favor and scientific research support from the leaders. With the support and encouragement of the leaders, the members of the scientific research team in universities continuously process cognitive information, thus generating creativity role identity, creativity self-efficacy, and knowledge creation willingness. This leads the members of university scientific research teams to become more aware of "who I am," "I can do it," and "I am willing to do it." In other words, they believe that they have the characteristics of innovation, constantly affirm their ability and experience to complete knowledge creation activities and have a 
strong willingness to create knowledge. As such, members can break the old practices and behaviors of knowledge creation and generate new processes and paradigms, thus promoting the generation of high-level scientific research results. Thus, we hypothesized the following:

Hypothesis 6a (H6a). A proactive personality significantly moderates individual creative role identity in the mediation between the LPIFT of the university scientific research team and individual creativity. The higher the level of an individual's proactive personality, the stronger the effect of the LPIFT of the university scientific research team on individual creativity through creative role identity, and vice versa.

Hypothesis $\mathbf{6 b} \mathbf{( H 6 b )}$. A proactive personality significantly moderates the mediating role of creative self-efficacy between the LPIFT of the university scientific research team and individual creativity. The higher the level of an individual's proactive personality, the stronger the effect of the LPIFT of the university scientific research team on individual creativity through creative self-efficacy, and vice versa.

Hypothesis 6c (H6c). A proactive personality significantly moderates the mediating role of individual willingness to create knowledge between the LPIFT of the university scientific research team and individual creativity. The higher the level of an individual's proactive personality, the stronger the effect of the LPIFT of the university scientific research team on individual creativity through individual willingness to create knowledge, and vice versa.

The above analysis indicates that the expectation from important others in the organization constructs the individual self-cognition, which in turn influences the individual's behavior. Therefore, in this study, the individual creative role identity, individual creative self-efficacy and individual willingness to create knowledge are considered as the mediating variables between the LPIFT of university scientific research teams and individual creativity. In addition, individual proactive personality is a relatively stable tendency to cause environmental changes, and it determines how individuals respond to changes in the surrounding environment. Therefore, our study introduces the individual proactive personality into the environment in which the LPIFT of university scientific research teams influences the individual self-cognition and further promotes the individual creativity, with the purpose to reveal the boundary reaction extent of the individual proactive personality to the individual self-cognition in this environmental system.

To summarize, we propose the corresponding conceptual model based on the hypotheses, as shown in Figure 1. This model analytically integrates both the moderators and mediators, referred to as the moderated mediation model [72]. Specifically, the effects of the LPIFT of the university scientific research team on the three mediators: individual creative role identity, individual creative self-efficacy, and individual willingness to create knowledge are linearly moderated by the proactive personality. The direct effects of the LPIFT and the three mediators on the individual creativity are also evaluated in the model. It is to note that the indirect effect from the LPIFT of the university scientific research team to the individual creativity is a function of the proactive personality. The indirect effect is estimated by multiplying the effect of the LPIFT on the mediator (role identity, self-efficacy, or willingness to create knowledge) and the effect of the mediator on individual creativity. As a result, the proactive personality as the moderator has a linear impact on this indirect effect. Whether this moderating effect is significant is examined based on the effect of the interaction (LPIFT $\times$ proactive personality) on the mediator (denoted as $a_{3 j}$ ) and the direct effect of the mediator on individual creativity (denoted as $b_{\mathfrak{j}}$ ), where $j$ indicates the $j^{\text {th }}$ mediator. The product of the two coefficients $a_{3 j} b_{j}$ is examined to address the significance of proactive personality on the indirect effect. 


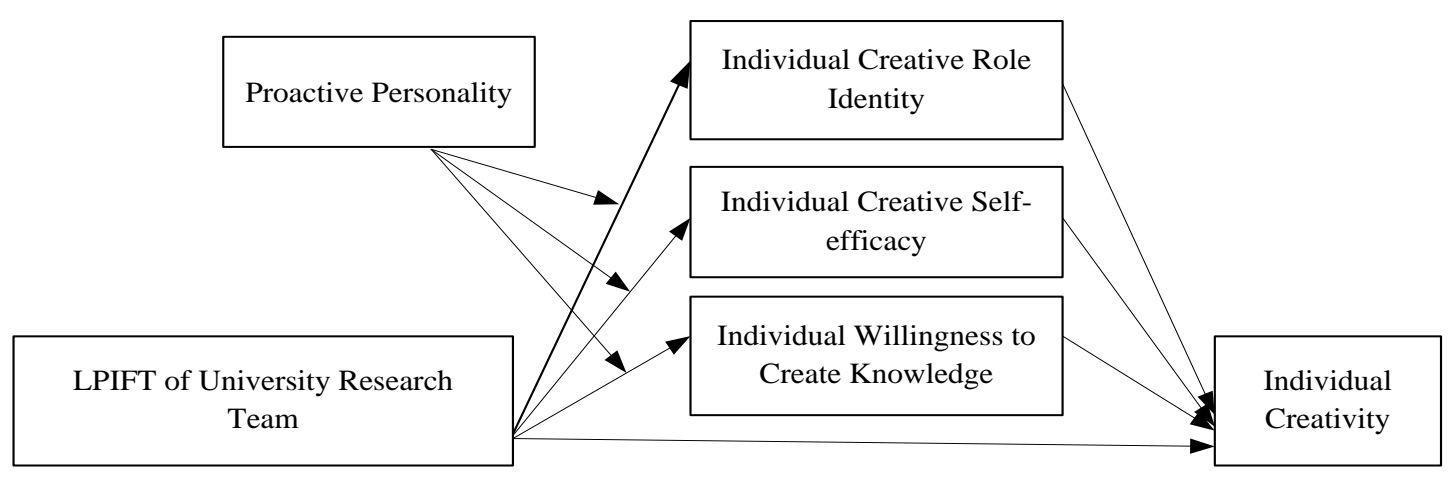

Figure 1. Hypothesized model.

\section{Methods}

\subsection{Participants and Procedure}

We mainly used a combination of field surveys and mail surveys to collect data. The following principles were adhered to when selecting research samples: (1) the operation time of the university scientific research team needed to be more than three years, and the team size more than three people; (2) the scientific research team was engaged in projects at or above the provincial and ministerial levels; (3) the academic backgrounds among the university scientific research teams should be as diverse as possible; and (4) the doctoral supervisor or postgraduate supervisor must have had at least three years of working experience as a supervisor. The questionnaires in this study were mainly obtained from the scientific research team of universities in Heilongjiang, Liaoning, and Jilin provinces. The research objects mainly included postgraduate supervisors, doctoral supervisors, postgraduates, and doctoral postgraduates. In the process of investigation, we mainly adopted the paired sample investigation method. The postgraduate supervisor completed the scale of the LPIFT of the university scientific research team, and the team members filled in their individual creative role identity, individual creative self-efficacy, individual willingness to create knowledge, proactive personality, and individual creativity scales.

A total of 550 questionnaires were distributed in this study. After supervisors and postgraduates or doctoral postgraduates were paired, 413 valid questionnaires were collected, and the effective collection rate was $75.09 \%$. Among them, 235 were men, accounting for $56.9 \%$, and 178 were women, accounting for $43.1 \%$. In terms of age distribution, the number of people from 25 to 29 years old was the largest at 124 , accounting for $30.0 \%$ of the sample. The second largest group was aged 30 to 34 , which was 108 people, accounting for $26.2 \%$. In terms of the distribution of professional titles, 43 professors, 91 associate professors, 128 lecturers, 16 assistants, and 135 others were surveyed, accounting for $10.4 \%, 22.0 \%, 31.0 \%, 3.9 \%$, and $32.7 \%$, respectively. In terms of education level, 236 doctors and above, 154 postgraduates, and 23 undergraduates were included, accounting for $57.1 \%, 37.3 \%$, and $5.6 \%$, respectively. From the perspective of working time in the team, the largest number of people in 2-3 years was 100 , accounting for $24.2 \%$, followed by 87 people in $3-5$ years, accounting for $21.1 \%$. In terms of the time distribution of team leadership, the most was five years ( $9.9 \%$ of the sample), followed by three years, accounting for $6.3 \%$. A total of 133 people had experience working as postgraduate or doctoral supervisors. In terms of the respective disciplines of the scientific research team, there were 88 in engineering, 94 in science, 96 in the arts, 116 in management, and 19 in others, accounting for $21.3 \%, 22.8 \%, 23.2 \%, 28.1 \%$, and $4.6 \%$, respectively.

\subsection{Measurement}

A survey was used in this research, covering demographic variables (sex, age, professional title, education level, tenure of work, tenure of leadership), LPIFT of the university scientific research 
team, individual creative role identity, individual creative self-efficacy, individual willingness to create knowledge, proactive personality, and individual creativity.

The measurements adopted in this research were selected from the literature and translated from English into Chinese by professional translators. We invited two bilingual professors from human resource management to check the accuracy of the Chinese version to ensure translation validity. Additionally, a pilot test among 50 people was conducted for the pre-test. The measurements for constructs used a five-point Likert scale (from $1=$ strongly disagree to $5=$ strongly agree) and were verified to be reliable (Cronbach's $\alpha>0.7$ ).

The LPIFT of the university scientific research team was measured using a nine-item scale from Wang [73]. This measurement was divided into three dimensions: knowledge (three items), ability (three items), and quality (three items). The Cronbach's $\alpha$ of this measurement was 0.933 .

The creative role identity was measured using a 3-item scale from Farmer et al. [49]. The Cronbach's $\alpha$ of this measurement was 0.812 . Creative self-efficacy was measured using a 4 -item scale from Tierney and Farmer [56]. The Cronbach's $\alpha$ of this measurement was 0.833 . The willingness to create knowledge was measured by a four-item scale from Fishbein and Ajzen [74]. The Cronbach's $\alpha$ of this measurement was 0.801 . Proactive personality was measured by an 11-item scale from Shang [75] translated from Bateman. The Cronbach's $\alpha$ of this measurement was 0.969 . Individual creativity was measured using a four-item scale from Farmer et al. [49]. The Cronbach's $\alpha$ of this measurement was 0.794 .

In this study, sex, age, professional title, education level, tenure of teamwork (in years), and the tenure of leadership (in years) were used as control variables. Except for the tenure of teamwork and the tenure of leadership, the rest were categorical variables.

\subsection{Data Analysis}

Data analysis was conducted using SPSS 21.0 (IBM Corp, Armonk, NY, USA) [76] and Mplus 7.4 (Muthén \& Muthén, Los Angeles, CA, USA) [77]. SPSS was used to calculate descriptive statistics and perform multiple regression analyses. Mplus was employed for the confirmatory factor analysis (CFA) [78] and moderated mediation analysis [72]. CFA was used to examine the structural factors in the survey on individual creativity promotion. The robust maximum likelihood estimation method was used for model estimation [79]. Candidate models were evaluated and compared based on the Chi-squared difference test, and various model goodness-of-fit indices, including comparative fit index (CFI) [76], the Tucker-Lewis Index (TLI) [80], root mean square error of approximation (RMSEA) [81], and standardized root mean square residual (SRMR) [82]. The moderated mediation analysis informs whether mediation effects significantly differed depending on the level of the moderator; that is, whether the indirect effect of a predictor on an outcome was conditional on the moderator. The moderated mediating effect was directly determined by the significance of $a_{3 j} b_{j}$ values [83]. Bootstrapping (sampling with replacement) with 1000 samples was used for obtaining standard errors (SEs) and 95\% confidence intervals (CIs) for the parameter estimates. All tests were performed at the significance level of 0.05 . The estimates of indirect effects from the LPIFT of scientific research teams to individual creativity through each of the three mediators (individual creative role identity, individual creative self-efficacy, and individual willingness to create knowledge) as a function of proactive personality were presented in plots produced by Mplus.

\section{Results}

\subsection{Confirmatory Factor Analysis}

As survey items were composed to measure six subscales; CFA was used to verify the factor structure of the instrument. With a sample size of 413 participants, we tested six CFA models with one to six latent factors. A summary of the model fit is shown in Table 1. The six-factor model with latent correlations yielded the best model fit overall, indicated by a significantly lower $\chi^{2}$ statistic, 
lowest RMSEA (0.045) and SRMR (0.037), and highest CFI (0.942) and TLI (0.936), compared with other models. The average variance extracted (AVE) values, computed as $A V E=\frac{\sum \lambda^{2}}{n}$, where $\lambda$ is the factor loading and $n$ is the sample size, were $0.578,0.522,0.504,0.517,0.747$, and 0.540 for the six subscales, respectively. The construct reliability (CR), calculated as $C R=\frac{\sum \lambda^{2}}{\sum \lambda^{2}+\sum \delta}$, where $\delta$ is the residual variance, was $0.925,0.766,0.802,0.810,0.970$, and 0.824 for the six subscales, respectively. All CR values were greater than 0.8 , indicating good reliability of each subscale. This confirmed that the survey had six latent factors. For the regression and moderated mediation analyses, we aggregated scores for each subscale and used the average to represent each subscale to reduce the model complexity.

Table 1. Results of confirmatory factor analysis (CFA) for the measurements of the variable studied. $(\mathrm{N}=413)$.

\begin{tabular}{cccccccc}
\hline Model & $\boldsymbol{X}^{\mathbf{2}}$ & $\mathbf{d f}$ & $\boldsymbol{X}^{\mathbf{2}} / d f$ & RMSEA & SRMR & CFI & TLI \\
\hline Six-factor Model & 1010.189 & 545 & 1.854 & 0.045 & 0.037 & 0.942 & 0.936 \\
\hline Five-factor Model $^{\mathrm{a}}$ & 1205.529 & 550 & 2.192 & 0.054 & 0.045 & 0.918 & 0.911 \\
\hline Four-factor Model $^{\mathrm{b}}$ & 1284.784 & 554 & 2.319 & 0.057 & 0.047 & 0.908 & 0.902 \\
\hline Three-factor Model $^{\mathrm{c}}$ & 2630.175 & 557 & 4.722 & 0.095 & 0.181 & 0.740 & 0.723 \\
\hline Two-factor Model $^{\mathrm{d}}$ & 3011.891 & 559 & 5.388 & 0.103 & 0.192 & 0.693 & 0.673 \\
\hline One-factor Model $^{2}$ & 4579.985 & 560 & 8.179 & 0.132 & 0.220 & 0.496 & 0.465 \\
\hline
\end{tabular}

Note: ${ }^{a}$ individual creative self-efficacy and individual willingness to create knowledge combined; ${ }^{\mathrm{b}}$ individual creative role identity, individual creative self-efficacy and individual willingness to create knowledge combined; ${ }^{c}$ individual creative role identity, individual creative self-efficacy, individual willingness to create knowledge and proactive personality combined; ${ }^{d}$ individual creative role identity, individual creative self-efficacy, individual willingness to create knowledge, proactive personality, and individual creativity combined.

\subsection{Descriptive Statistics}

The descriptive statistics for the aggregated scores of six subscales and other covariates are presented in Table 2. Correlation between the LPIFT of university scientific research teams and individual creativity was positive and significant $(r=0.308, p<0.01)$, confirming the first hypothesis. The LPIFT of university scientific research teams was correlated significantly and positively with individual creative role identity $(r=0.463, p<0.01)$, individual creative self-efficacy $(r=0.490, p<0.01)$, and individual willingness to create knowledge $(r=0.461, p<0.01)$. Individual creativity was also positively correlated with individual creative role identity $(r=0.462, p<0.01)$, individual creative self-efficacy $(r=0.527, p<0.01)$, and individual willingness to create knowledge $(r=0.405, p<0.01)$. These moderate and positive correlation estimates facilitated further investigations into the relationship among variables using causal modeling. 
Table 2. Means, standard deviations, and correlations $(\mathrm{N}=413)$.

\begin{tabular}{|c|c|c|c|c|c|c|c|c|c|c|c|c|c|c|}
\hline Variables & Mean & S.D. & 1 & 2 & 3 & 4 & 5 & 6 & 7 & 8 & 9 & 10 & 11 & 12 \\
\hline 1.Sex & 1.43 & 0.496 & 1 & & & & & & & & & & & \\
\hline 2.Age & 2.96 & 1.540 & -0.036 & 1 & & & & & & & & & & \\
\hline 3.Title & 3.37 & 1.320 & 0.015 & $-0.250 * *$ & 1 & & & & & & & & & \\
\hline 4.EDU & 2.52 & 0.602 & 0.067 & $0.470 * *$ & $-0.418^{* *}$ & 1 & & & & & & & & \\
\hline 5.TWT & 3.04 & 1.368 & 0.025 & $0.741^{* *}$ & -0.070 & & 1 & & & & & & & \\
\hline 6.LT & 2.00 & 3.576 & 0.000 & $0.883^{* *}$ & -0.057 & $0.175^{* *}$ & $0.590 * *$ & 1 & & & & & & \\
\hline 7.LPIFT & 4.3067 & 0.51958 & 0.022 & -0.104 * & 0.023 & -0.028 & -0.075 & -0.101 * & 1 & & & & & \\
\hline 8.RI & 4.2946 & 0.45936 & 0.066 & -0.086 & -0.015 & -0.048 & -0.075 & -0.067 & $0.463^{* *}$ & 1 & & & & \\
\hline 9.CS & 4.3341 & 0.46285 & 0.072 & -0.040 & -0.040 & -0.028 & -0.054 & -0.033 & $0.490 * *$ & $0.585^{* *}$ & 1 & & & \\
\hline 10.KW & 4.3166 & 0.49246 & 0.086 & 0.039 & -0.036 & $0.123 *$ & 0.054 & 0.002 & $0.461^{* *}$ & $0.511^{* *}$ & $0.477^{* *}$ & 1 & & \\
\hline 11.PP & 4.2485 & 0.78524 & -0.123 * & 0.021 & -0.009 & 0.049 & 0.005 & -0.017 & $0.344^{* *}$ & 0.103 * & 0.056 & $0.130 * *$ & 1 & \\
\hline 12.IC & 4.4104 & 0.44866 & 0.005 & 0.007 & -0.003 & 0.014 & -0.001 & 0.010 & $0.308^{* *}$ & $0.462 * *$ & $0.527^{* *}$ & $0.405^{* *}$ & 0.039 & 1 \\
\hline
\end{tabular}

Note: ${ }^{*} p<0.05 ; * *<0.001$. For simplicity, EDU, TWT, LT, LPIFT, RI, CS, KW, PP and IC represent education, the tenure of work, the tenure of leadership, LPIFT of university scientific research team, individual creative role identity, individual creative self-efficacy, individual willingness to create knowledge, proactive personality, and individual creativity. It is the same in the table below. 


\subsection{Multiple Regression Analysis}

In multiple regression analyses, factors that impact the individual creativity (outcome) were investigated. The impact of the six covariates were first examined (Model 1), followed by adding the LPIFT of university scientific research teams (Model 2) as a predictor of primary interest. The results of the two regression models are shown in Table 3. The LPIFT of university scientific research teams had a positive and significant impact on individual creativity $(\beta=0.269, p<0.001)$, where $\beta$ indicates the regression coefficient. All covariates had trivial effects on individual creativity. Overall, regression Model 2 explained 9.7\% of the variance in individual creativity. So, hypothesis H1 was supported.

Table 3. Main effect test results $(\mathrm{N}=413)$.

\begin{tabular}{ccc}
\hline \multirow{2}{*}{ Control Variables } & \multicolumn{2}{c}{ Individual Creativity(Y) } \\
\cline { 2 - 3 } & Model 1 & Model 2 \\
\hline Sex & 0.002 & -0.003 \\
\hline Age & -0.009 & -0.003 \\
\hline Title & 0.002 & 0.001 \\
\hline EDU & 0.031 & 0.025 \\
\hline TWT & -0.010 & -0.008 \\
\hline LT & 0.006 & 0.007 \\
\hline LPIFT $(X)$ & & 0.269 \\
\hline$R^{2}$ & 0.001 & 0.097 \\
\hline$F$ & 0.060 & $6.205 * * *$ \\
\hline$\Delta R^{2}$ & 0.001 & 0.096 \\
\hline$\Delta F$ & 0.060 & $43.040^{* * *}$ \\
\hline & Note: & $*<0.001$.
\end{tabular}

\subsection{Moderated Mediation Analysis}

To investigate the relationships among the six subscales, a moderated mediation analysis was conducted based on the theoretical model in Figure 1. In this model, individual creativity was the outcome of interest. The impact of the LPIFT of university scientific research teams on individual creativity was mediated through three factors: individual creative role identity, individual creative self-efficacy, and individual willingness to create knowledge. The mediation effects were moderated by a proactive personality at the first stage. Table 4 shows the coefficient estimates, standard errors, and $95 \%$ CIs from the moderated mediation model.

The results showed that at the significance level of 0.05 , the LPIFT of university scientific research teams had a significantly positive impact on all three mediators, indicated by the $\mathrm{a}_{11}, \mathrm{a}_{12}$, and $\mathrm{a}_{13}$ coefficient estimates of $0.442(\mathrm{LLCI}=0.345 ; \mathrm{ULCI}=0.540), 0.499(\mathrm{LLCI}=0.406$; $\mathrm{ULCI}=0.593)$, and $0.473(\mathrm{LLCI}=0.370 ; \mathrm{ULCI}=0.576)$, respectively (see Table 4$)$. The three mediators also had significantly positive impacts on individual creativity, with $b_{1}, b_{2}$, and $b_{3}$ estimates of 0.189 (LLCI $=0.067$; ULCI $=0.310), 0.350(\mathrm{LLCI}=0.234 ; \mathrm{ULCI}=0.466)$, and $0.133(\mathrm{LLCI}=0.021$; ULCI $=0.245)$, respectively. The direct effect of the LPIFT of university scientific research teams on individual creativity was not significant $\left(c_{1}=-0.019 ; \mathrm{LLCI}=-0.109 ; \mathrm{ULCI}=0.070\right)$, indicating that the three factors fully mediated the relationships from the LPIFT of university scientific research teams to individual creativity. This supported hypotheses $\mathrm{H} 2 \mathrm{a}, \mathrm{H} 2 \mathrm{~b}, \mathrm{H} 2, \mathrm{H} 3 \mathrm{a}, \mathrm{H} 3 \mathrm{~b}, \mathrm{H} 3, \mathrm{H} 4 \mathrm{a}, \mathrm{H} 4 \mathrm{~b}$, and $\mathrm{H} 4$. 
Table 4. Moderated mediation effect analysis $(\mathrm{N}=413)$.

\begin{tabular}{|c|c|c|c|c|c|c|c|c|c|c|}
\hline \multirow[b]{3}{*}{ LPIFT } & \multirow[b]{3}{*}{$a_{11}$} & \multicolumn{4}{|c|}{ RI } & \multicolumn{5}{|c|}{ CS } \\
\hline & & \multirow{2}{*}{$\begin{array}{c}\text { B } \\
0.442\end{array}$} & \multirow{2}{*}{$\begin{array}{c}\text { SE } \\
0.050\end{array}$} & \multicolumn{2}{|c|}{$95 \%$ CI } & \multirow[b]{2}{*}{$a_{12}$} & \multirow{2}{*}{$\begin{array}{c}\text { B } \\
0.499\end{array}$} & \multirow{2}{*}{$\begin{array}{c}\text { SE } \\
0.048\end{array}$} & \multicolumn{2}{|c|}{$95 \%$ CI } \\
\hline & & & & 0.345 & 0.540 & & & & 0.406 & 0.593 \\
\hline \multicolumn{11}{|l|}{ RI } \\
\hline \multicolumn{11}{|l|}{ CS } \\
\hline \multicolumn{11}{|l|}{ KW } \\
\hline $\mathrm{PP}$ & $a_{21}$ & 0.022 & 0.036 & -0.049 & 0.092 & $a_{22}$ & -0.009 & 0.029 & -0.066 & 0.048 \\
\hline LPIFT*PP $^{*}$ & $a_{31}$ & 0.098 & 0.036 & 0.028 & 0.168 & $a_{32}$ & 0.118 & 0.032 & 0.055 & 0.180 \\
\hline Sex & $\mathrm{U}_{11}$ & 0.051 & 0.041 & -0.030 & 0.131 & $\mathrm{U}_{12}$ & 0.053 & 0.041 & -0.027 & 0.133 \\
\hline Age & $\mathrm{U}_{21}$ & -0.028 & 0.041 & -0.109 & 0.052 & $\mathrm{U}_{22}$ & 0.009 & 0.042 & -0.074 & 0.093 \\
\hline Title & $\mathrm{U}_{31}$ & -0.023 & 0.018 & -0.059 & 0.014 & $\mathrm{U}_{32}$ & -0.025 & 0.019 & -0.061 & 0.012 \\
\hline EDU & $\mathrm{U}_{41}$ & -0.035 & 0.053 & -0.0140 & 0.069 & $\mathrm{U}_{42}$ & -0.043 & 0.049 & -0.139 & 0.053 \\
\hline TWT & $\mathrm{U}_{51}$ & 0.004 & 0.027 & -0.049 & 0.058 & $\mathrm{U}_{52}$ & -0.007 & 0.025 & -0.057 & 0.043 \\
\hline LT & $\mathrm{U}_{61}$ & 0.006 & 0.015 & -0.023 & 0.035 & $\mathrm{U}_{62}$ & -0.001 & 0.017 & -0.034 & 0.032 \\
\hline Intercept & $\mathrm{i}_{\mathrm{m} 1}$ & 0.138 & 0.155 & -0.166 & 0.443 & $\mathrm{i}_{\mathrm{m} 2}$ & 0.095 & 0.154 & -0.207 & 0.396 \\
\hline \multicolumn{6}{|c|}{$\mathrm{R}^{2}=0.240^{* * *}$} & \multicolumn{5}{|c|}{$\mathrm{R}^{2}=0.283^{* * *}$} \\
\hline & \multicolumn{5}{|c|}{ KW } & & \multicolumn{4}{|c|}{ IC } \\
\hline & & B & SE & \multicolumn{2}{|c|}{$95 \%$ CI } & & B & SE & \multicolumn{2}{|c|}{$95 \%$ CI } \\
\hline LPIFT & $\mathrm{a}_{13}$ & 0.473 & 0.053 & 0.370 & 0.576 & $c_{1}$ & -0.019 & 0.046 & -0.109 & 0.070 \\
\hline RI & & & & & & $b_{1}$ & 0.189 & 0.062 & 0.067 & 0.310 \\
\hline CS & & & & & & $\mathrm{b}_{2}$ & 0.350 & 0.059 & 0.234 & 0.466 \\
\hline KW & & & & & & $b_{3}$ & 0.133 & 0.057 & 0.021 & 0.245 \\
\hline PP & $a_{23}$ & 0.027 & 0.040 & -0.051 & 0.105 & & & & & \\
\hline LPIFT*PP $^{*}$ & $a_{33}$ & 0.092 & 0.053 & -0.012 & 0.196 & & & & & \\
\hline Sex & $\mathrm{U}_{13}$ & 0.070 & 0.044 & -0.016 & 0.157 & U14 & -0.044 & 0.038 & -0.120 & 0.031 \\
\hline Age & $\mathrm{U}_{23}$ & 0.026 & 0.043 & -0.057 & 0.110 & U24 & -0.002 & 0.032 & -0.065 & 0.061 \\
\hline Title & $\mathrm{U}_{33}$ & 0.006 & 0.020 & -0.032 & 0.045 & U34 & 0.012 & 0.016 & -0.019 & 0.044 \\
\hline EDU & $\mathrm{U}_{43}$ & 0.095 & 0.060 & -0.023 & 0.213 & U44 & 0.029 & 0.047 & -0.063 & 0.120 \\
\hline TWT & $\mathrm{U}_{53}$ & -0.011 & 0.026 & -0.062 & 0.041 & U54 & -0.005 & 0.024 & -0.052 & 0.042 \\
\hline $\mathrm{LT}$ & $\mathrm{U}_{63}$ & -0.005 & 0.017 & -0.038 & 0.028 & U64 & 0.005 & 0.012 & -0.018 & 0.029 \\
\hline Intercept & $\mathrm{i}_{\mathrm{m} 3}$ & -0.408 & 0.167 & -0.735 & -0.081 & $\mathrm{i}_{\mathrm{mY}}$ & -0.040 & 0.138 & -0.311 & 0.233 \\
\hline \multicolumn{6}{|c|}{$\mathrm{R}^{2}=0.250^{* * *}$} & \multicolumn{5}{|c|}{$\mathrm{R}^{2}=0.272^{* * *}$} \\
\hline $\mathrm{a}_{31} \mathrm{~b}_{1}$ & & 0.019 & 0.009 & 0.002 & 0.036 & $a_{32} b_{2}$ & 0.041 & 0.013 & 0.016 & 0.066 \\
\hline$a_{33} b_{3}$ & & 0.012 & 0.009 & -0.005 & 0.029 & & & & & \\
\hline
\end{tabular}

Note: The central value is used in the analysis of each variable, and each coefficient is nonstandardized value; $* * * p<0.001$.

The interaction between the LPIFT of university scientific research teams and proactive personality significantly and positively affected two mediators, individual creative role identity and individual creative self-efficacy, with $\mathrm{a}_{31}$ and $\mathrm{a}_{32}$ estimates of 0.098 (LLCI $=0.028$; ULCI $=0.168$ ) and 0.118 $(\mathrm{LLCI}=0.055 ; \mathrm{ULCI}=0.180)$, respectively. This indicated that a proactive personality significantly and positively moderated the relationship from LPIFT of university scientific research teams to individual creative role identify or individual creative self-efficacy. Therefore, H5a and H5b were assumed to be 
supported. However, the interaction between the LPIFT of university scientific research teams and proactive personality had no significant effect on willingness to create knowledge, with an $\mathrm{a}_{33}$ estimate of 0.092 (LLCI $=-0.012 ; \mathrm{ULCI}=0.196$ ). This indicated that a proactive personality had no significantly positive moderating effects on the LPIFT of university scientific research teams and the willingness to create knowledge; thus, hypothesis H5c was not supported.

The indirect effect of the LPIFT of university scientific research teams on individual creativity through each of the three mediators is a function of the proactive personality moderator, computed as $\mathrm{b}_{j}{ }^{*}\left(\mathrm{a}_{1 \mathrm{j}}+\mathrm{a}_{3 \mathrm{j}} \mathrm{PP}\right)$ [72]. The moderating effect was indicated by the coefficient $\mathrm{a}_{3 \mathrm{j}} \mathrm{b}_{\mathrm{j}}$, as shown in Table 4 . A proactive personality significantly moderated the mediation through individual creative role identity $\left(\mathrm{a}_{31} \mathrm{~b}_{1}=0.019 ; p<0.05 ; \mathrm{LLCI}=0.002 ; \mathrm{ULCI}=0.036\right)$ and individual creative self-efficacy $\left(\mathrm{a}_{32} \mathrm{~b}_{2}=0.041\right.$; $p<0.05$; LLCI $=0.016$; ULCI $=0.066$ ). Thus, the indirect effects of LPIFT of university scientific research teams on individual creativity through each of the two mediators (individual creative role identity and individual creative self-efficacy) as a function of the proactive personality moderator are further plotted in Figures 2 and 3, respectively. However, the mediating effect indicator $\mathrm{a}_{33} \mathrm{~b}_{3}=0.012$ $(\mathrm{LLCI}=-0.005 ; \mathrm{ULCI}=0.029)$ was not significant, indicating that the moderating effect of individual proactive personality on the mediating effect of willingness to create knowledge was not valid.

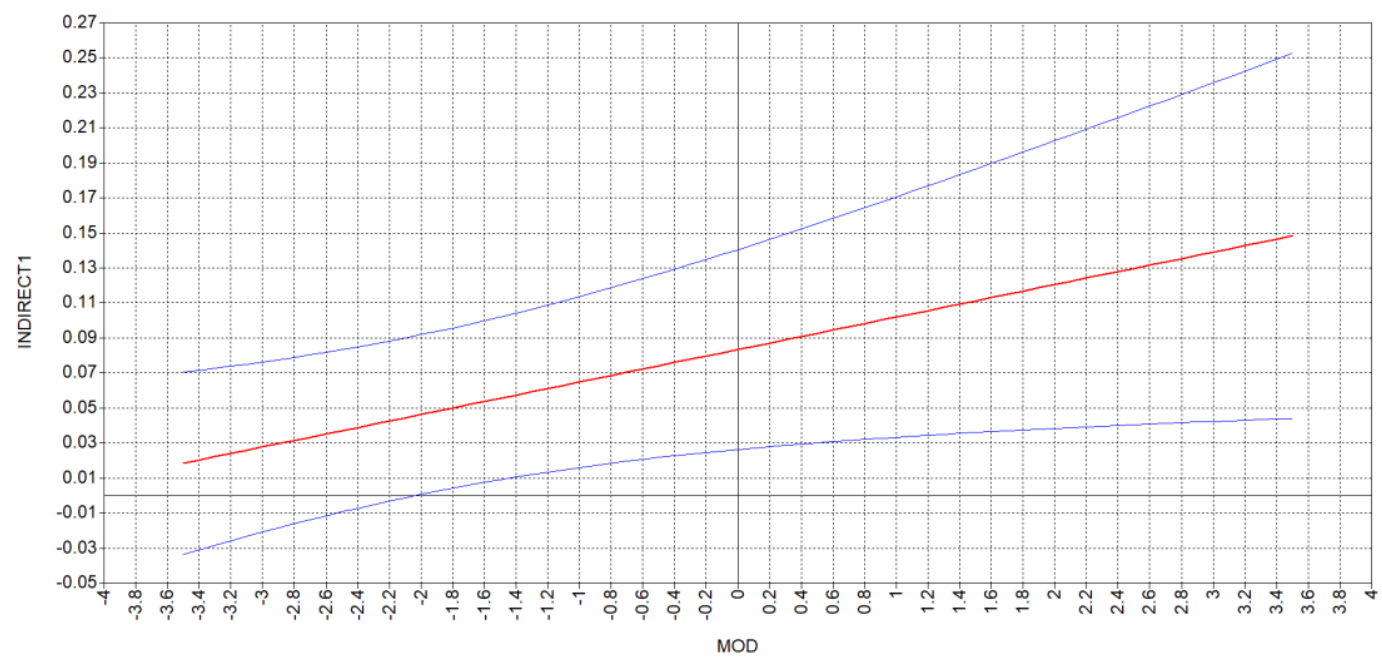

Figure 2. Indirect effects of leaders' positive and implicit followership theory (LPIFT) of university scientific research team on individual creativity through individual creative role identity as a function of proactive personality.

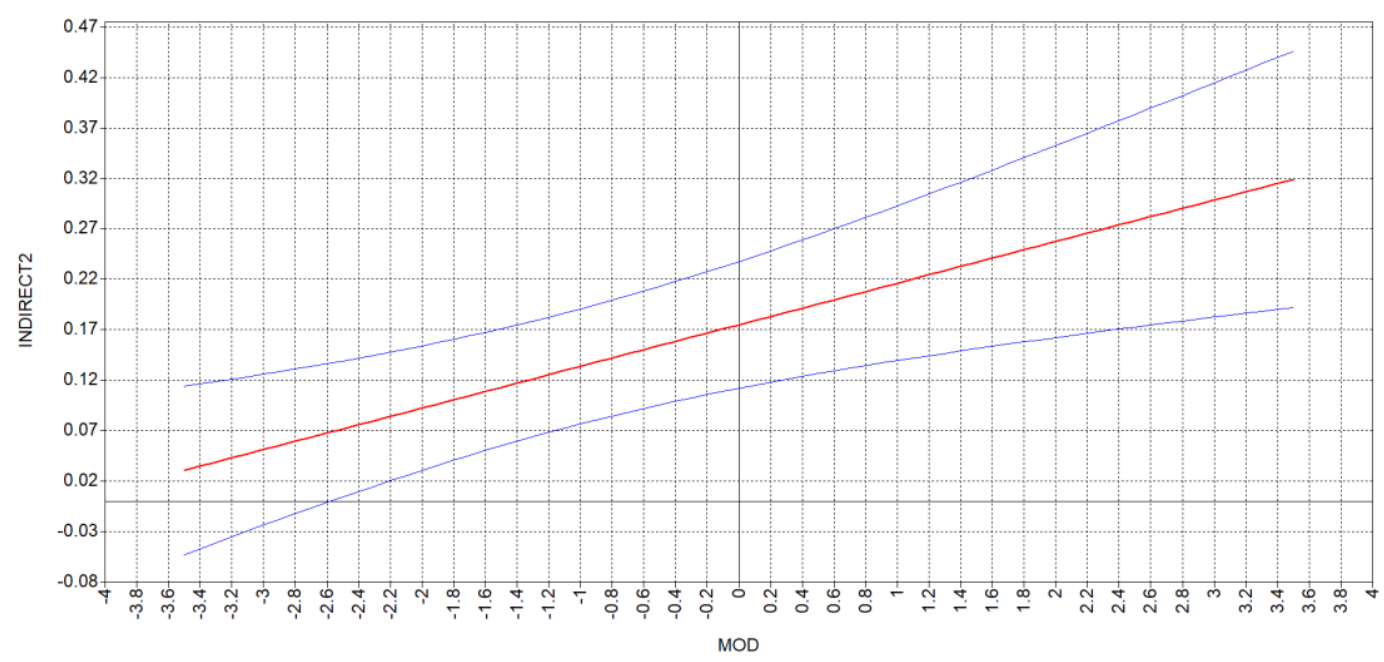

Figure 3. Indirect effects of LPIFT of university scientific research team on individual creativity through individual creative self-efficacy as a function of proactive personality. 
In Figures 2 and 3, the $x$-axis indicates the value of the moderator ranges from -3.5 to 3.5 , given that all values of proactive personality were within \pm 3.5 in the sample. The graphs were drawn based on 0.1 increments from -3.5 to 3.5 in the moderator values using Mplus. The y-axis shows the indirect effect of LPIFT of university scientific research teams on individual creativity. The red line shows the point estimates of indirect effects given the moderator values, and the blue curves indicate the upper and lower bounds of the $95 \%$ confidence intervals of indirect effect estimates.

Both Figures 2 and 3 suggest a positive impact of the moderator on the indirect effect estimate; as the moderator value increased, the indirect effect estimate increased. Specifically, for the mediation through individual creativity role identity in Figure 2, the indirect effect of the LPIFT of university scientific research teams on individual creativity was significant (varying between 0 and 0.26 ) when the proactive personality moderator was greater than -2.0. For the mediation through individual creative self-efficacy in Figure 3, the indirect effect of the LPIFT on individual creativity was significant (varying between 0 and 0.45 ) when proactive personality was greater than -2.6 . For moderator values that were smaller than the cutoffs reported above for the two moderated mediations, the indirect effects of the LPIFT of university scientific research teams on individual creativity were not significant.

\section{Discussion}

This study examined the mediating role of individual creative role identity, individual creative self-efficacy, individual willingness to create knowledge in the relationship between the LPIFT of university scientific research teams and individual creativity and explored whether this mediating effect was moderated by individual proactive personality. The current study contributes to the LPIFT literature by stretching our understanding of whether and to what extent the LPIFT of university scientific research team leaders affects individual creativity and how this relationship is mediated and moderated by various variables of interest.

Findings echoed our research hypotheses in which the individual creativity role identity, individual creativity self-efficacy and individual knowledge creation willingness fully mediated the relationship between the LPIFT of university scientific research team and individual creativity. Consistent with previous studies, when the LPIFT is established and activated, we observed the development of related psychology and behaviors [10]. A proactive personality was found to positively moderate the relationship between the LPIFT of university scientific research teams and individual creativity through individual creative role identity and individual creative self-efficacy, respectively. The higher the level of the proactive personality, the stronger the effect of the LPIFT of university scientific research teams on individual creative role identity or individual creative self-efficacy. Moreover, a higher level of proactive personality resulted in a stronger indirect effect of the LPIFT on individual creativity through individual creative role identity or individual creative self-efficacy. These findings are consistent with the literature suggesting that the relationship between proactive personality and environment is relatively close, and a good team atmosphere is conducive to the role of proactive personality [84].

It is to note that the moderating effect of a proactive personality on the relationship between the LPIFT and individual willingness to create knowledge was not significant, neither was the influence of proactive personality on the indirect effect from the LPIFT to individual creativity. These findings are in line with previous studies suggesting that the individual proactive personality plays a different role under different environmental conditions [85].

\subsection{Theoretical Implications}

The theoretical contributions of this study lay in the following aspects. First, university research teams are an important force of national scientific and technological innovation. Due to their organizational structure, member allocation, goal appeal, and other characteristics, the team has a natural demand and desire for creativity. However, previous research only considered the theory of leadership externality. Therefore, research on promotion of individual creativity in university scientific 
research teams, from the perspective of IFT, not only expands the validity of IFT but also provides a new research perspective for the promotion of individual creativity in the team.

Second, we integrated the LPIFT of university scientific research teams, individual creative role identity, individual creative self-efficacy, individual willingness to create knowledge, and individual creativity into a research framework. This opens the black box between the LPIFT of university scientific research teams and individual creativity. We systematically and comprehensively revealed how individual creative role identity, individual creative self-efficacy, and individual knowledge creation willingness play a mediating role between the LPIFT of university scientific research teams and individual creativity. The research results further clarify the theoretical path through which the LPIFT of university scientific research teams promotes individual creativity through individual psychological cognition.

Third, our findings not only reveal the moderating effect of proactive personality on the LPIFT of university scientific research teams and individual psychological self-cognition (individual creative role identity, individual creative self-efficacy, and individual willingness to create knowledge), but also reveal the moderating effect of proactive personality on individual psychological self-cognition (individual creative role identity, individual creative self-efficacy, and individual willingness to create knowledge). The findings further expand upon how the boundaries of individual psychological cognition, which have a mediating role between the LPIFT of university scientific research teams and individual creativity, are influenced by a proactive personality. The results have important theoretical significance for future research on the promotion of individual creativity by LPIFT of university scientific research teams from the perspective of self-cognition.

Fourth, on the one hand, this research further promotes the development of IFT, creativity theory, social cognition theory, and proactive personality theory. On the other hand, it provides relevant research approaches for enterprises, governments, research institutes, and other organizations to improve individual creativity.

Fifth, this study visualized the moderated mediating effect in the moderated mediating effect diagrams, making the research results intuitive and graphical. The methodology used also provided a reference for the test of moderated mediating effects in organizational psychology.

\subsection{Practical Implications}

The practical implication of this study is to put forward strategies to enhance the individual creativity of university scientific research team from the perspective of LPIFT, self-psychological cognition theory, proactive personality theory. This can only provide practical guidance for the improvement of individual creativity of Chinese university scientific research teams and also provide theoretical reference and decision basis for relevant management and decision departments. Moreover, it is of great practical significance to solve the bottleneck of the sustainable development of the university scientific research teams in China and to enhance the competitiveness of the university scientific research teams and individuals in China and even the competitiveness of Chinese universities in the global scale.

First, the results show that the LPIFT of university scientific research teams has a significant positive impact on individual creativity. So university scientific research team leaders should set up a positive follower prototype. For the university scientific research team, the postgraduate supervisor is the main leader of the scientific research team while the postgraduate is the main follower on the team. The positive follower prototype of the postgraduate supervisor plays a crucial role in the development of the whole scientific research team and of the postgraduates. Therefore, the postgraduate supervisor of the university scientific research team should build a positive follower prototype from three aspects—-knowledge, ability, and quality.

Second, the influence of LPIFT of university scientific research teams on individual creativity is mediated by individual creative role identity, individual creative self-efficacy, and individual willingness to create knowledge. This indicates that in the process of promoting individual creativity 
in university scientific research teams, we should not only start with the prototype of positive followers established by leaders, but we should also pay attention to shaping and improving the individual creative identity, individual creative self-efficacy, and individual willingness to create knowledge of team members. Only by working together can individual creativity be promoted effectively.

Third, the managers and postgraduate supervisors of university scientific research teams should also pay attention to how individual proactive personality of team members can strengthen the positive effect of the LPIFT on the individual creative role identity and individual creative efficacy, and can mediate the effect of strengthening individual creative role identity and individual creative efficacy. It was revealed that the proactive personality significantly moderated the mediating effects of individual creative role identity and individual creative self-efficacy. When the individual proactive personality was greater than 2 , the indirect effect through individual creative role identity was significant and gradually strengthened from 0 to 0.26 . When the individual proactive personality was greater than -2.6 , the indirect effect through individual creative self-efficacy was significant and gradually enhanced from 0 to 0.45 . This provides management directions in the combination of individual and situational factors for the promotion of individual creativity. Individual proactive personality is the tendency of team members to actively seek change or improvement. If proactive personality can be stimulated, individual creative role identity will be promoted and individual creative self-efficacy will be enhanced, to promote individual creativity.

\subsection{Limitations and Future Research}

Although the research results presented here have certain reference value for the promotion of individual creativity of university scientific research teams, some deficiencies are outlined below.

First, the research objects of this paper were mainly postgraduates, postgraduate supervisors, doctoral postgraduates, and doctoral supervisors of university scientific research teams in three provinces of Northeast China, so there were certain limitations in sample size and external validity. In the future, the selection of research objects should cover universities across the country as much as possible, to improve the universality and validity of the research. This will further improve practical applications of the research conclusions for the enhancement of individual creativity of university scientific research teams.

Second, we mainly adopted a cross-sectional research design. That is, six variables were collected simultaneously, which may lead to failure to accurately and truthfully reveal causal relationships between variables. A certain time span of the influence should exist from the LPIFT of university scientific research teams to the individual creative role identity, individual creative self-efficacy, individual willingness to create knowledge, and proactive personality to the promotion of individual creativity. If the data are collected at one point in time, some influencing factors may have been ignored. Therefore, longitudinal studies can be adopted in the future.

Thirdly, in this study, we found that the positive moderating effect of individual proactive personality on the LPIFT of university scientific research teams and individual willingness to create knowledge was not significant. Also, the moderating effect of proactive personality on individual willingness to create knowledge was not significant. However, this has not been further studied. In the future, we could further explore the underlying reasons for the insignificance of this moderating role.

\section{Conclusions}

This study advances our understanding of how the LPITF of university scientific research teams promote individual creativity through individual creative role identity, individual creative self-efficacy and individual willingness to create knowledge in the condition of individual proactive personality. Considering the important role of individual creativity promotion in university scientific innovation system, the main purpose of this study is to explore the creative psychological process of university scientific research team LPIFT that affects individual creativity from the perspective of individual self-cognition. We found that the LPIFT of university scientific research teams increased individual 
creative role identity, individual creative self-efficacy and individual willingness to create knowledge, and further improved individual creativity. The findings thus supported the hypothesis that individual creative role identity, individual creative self-efficacy and individual willingness to create knowledge plays a mediating role in the relationship between the LPIFT of university scientific research team and individual creativity. Furthermore, through a moderated mediation model, we also found that the mediating relationship from the LPIFT to individual creativity through individual creative role identity and individual creative self-efficacy was moderated by individual proactive personality. Specifically, the indirect effect of the LPIFT of university scientific research team on individual creativity through individual creative role identity and individual creative self-efficacy was stronger when individual proactive personality was higher. Nevertheless, the indirect effect through individual willingness to create knowledge is not moderated by individual proactive personality. A future research direction would be to improve the understanding of the value of the LPIFT of university scientific research teams and the process of individual creativity.

Author Contributions: Conceptualization, L.W.; methodology, L.W. and X.L.; software, L.W. and X.L.; validation, L.W. and X.L.; formal analysis, L.W.; investigation, L.W.; data curation, L.W.; writing-original draft preparation, L.W. and X.L.; visualization, X.L.; writing—review and editing, L.W. and X.L.; funding acquisition, L.W. All authors have read and agreed to the published version of the manuscript.

Funding: This research was funded by the National Natural Science Foundation of China (71704020), the Natural Science Foundation of Heilongiiang Province (QC2017081), the "Academic Backbone" Project of Northeast Agricultural University (18XG29), the Overseas Study Fund Project of Ministry of Education (201806615041), and the Heilongjiang Postdoctoral Startup Project (LBH-Q17019).

Conflicts of Interest: The authors declare no conflict of interest.

\section{References}

1. Wang, D.X.; Xue, H.J.; Zhang, D.F. The promotion of creativity and 'far-off hybridization'-Take the university research team as an example. Sci. Sci. Manag. Sci. Technol. 2009, 30, 182-185.

2. Gumusluoglu, L.; Ilsev, A. Transformational Leadership, Creativity, and Organizational Innovation. J. Bus. Res. 2009, 62, 461-473. [CrossRef]

3. Zhang, A.Y.; Tsui, A.S.; Wang, D.X. Leadership behavior and group creativity in Chinese organization: The role of group processes. Leadersh. Q. 2011, 22, 851-862. [CrossRef]

4. Antonakis, J.; House, R.J. Instrumental leadership: Measurement and extension of transformationaltransactional leadership theory. Leadersh. Q. 2014, 25, 746-771. [CrossRef]

5. Bass, B.M. Leadership and Performance beyond Expectations; Free Press: New York, NY, USA, 1985; 14p.

6. Deliu, D. Empathetic leadership-Key element for inspiring strategic management and a visionary effective corporate governance. J. Emerg. Trends. Mark. Manag. 2019, 1, 280-292.

7. Carsten, M.K.; Uhl-bien, M.; West, B.J.; Patera, J.L.; McGregor, R. Exploring social constructions of followership: A qualitative study. Leadersh. Q. 2010, 21, 543-562. [CrossRef]

8. Nina, M.J.; Sebastian, S.; Stephan, B.; Rolf, V.D. The ideal and the counter-ideal follower-advancing implicit followership theories. Leadersh. Organ. Dev. J. 2016, 37, 1205-1222.

9. Sy, T. What do you think of followers? Examining the content, structure, and consequences of implicit followership theories. Organ. Behav. Hum. Decis. Process. 2010, 113, 73-84. [CrossRef]

10. Epitropaki, O.; Sy, T.; Martin, R.; Tram-Quon, S.; Topakas, A. Implicit leadership and followship theories "in the wild": Taking stock of informaiton-processing approaches to leadership and follwership in organization settings. Leadersh. Q. 2013, 24, 858-881. [CrossRef]

11. Keller, T. Images of the familiar: Individual differences and implicit leadership theories. Leadersh. Q. 1999, 10, 589-607. [CrossRef]

12. Derler, A.; Weibler, J. The ideal employee: Context and leaders' implicit follower theories. Leadersh. Organ. Dev. J. 2014, 35, 2-12. [CrossRef]

13. Hoption, C.; Christie, A.; Barling, J. Submitting to the follower label: Followership, positive affect, and extra-role behaviors. Z. Psychol. 2012, 220, 221-230. [CrossRef]

14. Whiteley, P.; Sy, T.; Johnson, S.K. Leaders' conceptions of followers: Implications for naturally occurring pygmalion effects. Leadersh. Q. 2012, 23, 822-834. [CrossRef] 
15. Duong, J. Leader's Conceptions and Evaluations of Followers as Antecedents of Leadership Style, Leader-Member Exchange and Employee Outcomes. Ph.D. Thesis, Alliant International University, San Francisco, CA, USA, 2011.

16. Gralewski, J.; Karwowski, M. Are teachers' implicit theories of creativity related to the recognition of their students' creativity? J. Creat. Behav. 2016, 52, 156-167. [CrossRef]

17. Stanislav, N. Implicit theories of creativity of secondary school students from Estonia and Russia: Effects of collectivism, Individualism, and a bilingual educational environment. Creat. Res. J. 2017, 29, 56-62.

18. Zhang, Z.Y.; Zhao, S.M.; Zhou, L.L.; Qin, W.P. Research on the influence of implicit coordination on team creativity-the moderating effect of task characteristics. Sci. Sci. Manag. Sci. Technol. 2014, 35, 173-180.

19. Zhao, W.; Li, F.M.; Gao, Y.; Qin, H.X. The influence of individual-organization matching and implicit coordination on the creativity of cross-functional teams: The moderating effect of insider identity perception. Sci. Sci. Manag. Sci. Technol. 2016, 37, 149-160.

20. Fan, G.G.; Li, C.Q.; Zhao, X.J. The relationship between implicit self-esteem and explicit self-esteem and creative tendency in college students. Educ. Teach. BBS 2012, 34, 167-168.

21. Ahmad, I.; Zafar, M.A.; Shahzad, K. Authentic leadership style and academia's creativity in higher education institutions: Intrinsic motivation and mood as mediators. Transylv. Rev. Adm. Sci. 2015, 46, 5-19.

22. Wang, D.X.; Hong, Y. Research on the mechanism of leadership support behavior promoting employee creativity. Nankai Manag. Rev. 2010, 13, 109-114.

23. Moss, S.A.; Ritossa, D.A. The impact of goal orientation on the association between leadership style and follower performance, creativity and work attitude. Leadership 2007, 34, 433-456. [CrossRef]

24. Asif, M.; Qing, M.; Hwang, J.; Shi, H. Ethical leadership, affective commitment, work engagement, and creativity: Testing a multiple mediation approach. Sustainability 2019, 11, 4489. [CrossRef]

25. Huang, S.; Chen, J.; Mei, L.; Mo, W. The effect of heterogeneity and leadership on innovation performance: Evidence from university research teams in China. Sustainability 2019, 11, 4441. [CrossRef]

26. Ghabban, F.; Selamat, A.; Ibrahim, R.; Krejcar, O.; Maresova, P.; Herrera-Viedma, E. The influence of personal and organizational factors on researchers' attitudes towards sustainable research productivity in Saudi universities. Sustainability 2019, 11, 4804. [CrossRef]

27. Newman-Storen, R. Leadership in sustainability: Creating an interface between creativity and leadership theory in dealing with "Wicked Problems". Sustainability 2014, 6, 5955-5967. [CrossRef]

28. Wang, P.; Zhu, W.C. Mediating role of creative identity in the influence of transformational leadership on creativity: Is there a multilevel effect? J. Leadersh. Organ. Stud. 2011, 18, 25-39. [CrossRef]

29. Jaiswal, N.K.; Dhar, R.L. Fostering employee creativity through transformational leadership: Moderating role of creative self-efficacy. Creat. Res. J. 2016, 28, 367-371. [CrossRef]

30. Wang, G.Y.; Zhang, W.J.; Chen, G.; Liu, F. 'I am', 'I can' and 'I will'-the influence of work passion on employees' creativity. Hum. Resour. Dev. China 2016, 11, 28-35.

31. Richter, A.W.; Hirst, G.; van Knippenberg, D.; Baer, M. Creative self-efficacy and individual creativity in team contexts: Cross-level interactions with team informational resources. J. Appl. Psychol. 2012, 97, 1282-1290. [CrossRef]

32. Yip, J. How Implicit Assumptions about Followers Shape the Mentoring Behavior of Top Executives; Academy of Management: Briarcliff Manor, NY, USA, 2013.

33. Guo, Y.H.; Lan, L. The negative cognition of leaders leads to the turnover intention of subordinates-the role of emotional exhaustion and psychological capital from the perspective of implicit following theory. Tech. Econ. Manag. Stud. 2018, 10, 64-67.

34. Grant, J.M.; Kim, T.Y.; Wang, J. Dispositional antecedents of demonstration and usefulness of voice behavior. J. Bus. Psychol. 2011, 26, 285-297.

35. Roopak, K.; Mishra, S.; Sikarwar, E. Linking leader-follower proactive personality congruence to creativity. Pers. Rev. 2019, 48, 454-470. [CrossRef]

36. Simon, L.S.; Bauer, T.N.; Erdogan, B.; Shepherd, W. Built to last: Interactive effects of perceived overqualification and proactive personality on new employee adjustment. Pers. Psychol. 2019, 72, 213-240. [CrossRef]

37. Shin, Y.; Eom, C. Team proactivity as a linking mechanism between team creative efficacy, transformational leadership, and risk-Taking norms and team creative performance. J. Creat. Behav. 2014, 48, 89-114. [CrossRef] 
38. Tang, Y.H.; Zhao, S.H. Leader-member exchange relationship, insider identity cognition and employee creativity-the moderating effect of proactive personality. Chin. Pers. Sci. 2018, 12, 38-45.

39. Zhang, J.; Bal, P.M.; Akhtar, M.N.; Long, L.; Zhang, Y.; Ma, Z.X. High-performance work system and employee performance: The mediating roles of social exchange and thriving and the moderating effect of employee proactive personality. Asia. Pac. J. Hum. Resour. 2019, 57, 369-395. [CrossRef]

40. Hu, R.; Wang, L.; Zhang, W.; Bin, P. Creativity, proactive personality, and entrepreneurial intention: The role of entrepreneurial alertness. Front. Psychol. 2018, 9, 1-10. [CrossRef]

41. Li, M.J.; Wang, Z.H.; Gao, J.; You, X.Q. Proactive personality and job satisfaction: The mediating effects of self-efficiency and work engagement in teachers. Curr. Psychol. 2017, 36, 48-55. [CrossRef]

42. Bakker, A.B.; Tims, M.; Derks, D. Proactive personality and job performance: The role of job crafting and work engagement. Hum. Relat. 2012, 65, 1359-1378. [CrossRef]

43. Kuo, C.C.; Ye, Y.C.; Chen, M.Y.; Chen, L.H. Proactive personality enhances change in employees' job satisfaction: The moderating role of psychological safety. Aust. J. Manag. 2019, 44, 482-494. [CrossRef]

44. Epitropaki, O.; Martin, R. Implicit leadership theories in applied settings: Factor structure, generalizability, and stability over time. J. Appl. Psychol. 2004, 89, 293-310. [CrossRef]

45. Zhu, Z.B.; Chen, L.L.; Liang, Y.T. Influence of implicit followership theory on employee innovation behavior: The role of leadership support and internal motivation. Hum. Resour. Dev. China 2017, 7, 16-24.

46. Szumski, G.; Karwowski, M. Exploring the Pygmalion effect: The role of teacher expectations, academic self-concept, and class context in students' math achievement. Contemp. Educ. Psychol. 2019, 59, 1-10. [CrossRef]

47. Scott, S.G.; Bruce, R.A. Determinants of innovative behavior: A path model of individual innovation in the workplace. Acad. Manag. J. 1994, 37, 580-607.

48. Petkus, E. The creative identity: Creative behavior from the symboli interactionist perspective. J. Creat. Behav. 1996, 30, 188-196. [CrossRef]

49. Farmer, S.M.; Tierney, P.; Kung-Mcintyre, K. Employee creativity in Taiwan: A application of role identity. Acad. Manag. J. 2003, 46, 618-630.

50. Yin, K.; Sun, J.M.; Xing, L.; Yang, X.J. The influence of postgraduates' research role identification on research creativity: The role of inclusive tutors of leadership and the management atmosphere of teachers' mistakes. Psychol. Dev. Educ. 2016, 32, 557-564.

51. Wang, C.-J.; Tsai, H.-T.; Tsai, M.-T. Linking transformational leadership and employee creativity in the hospitality industry: The influences of creative role identity, creative self-efficacy, and job complexity. Tour. Manag. 2013, 40, 79-89. [CrossRef]

52. Callero, P.L. Role-identity salience. Soc. Psychol. Q. 1985, 48, 201-215. [CrossRef]

53. Callero, R.L.; Howard, J.A.; Piliavin, J.A. Helping behavior as role behavior: Disclosing social structure and history in the analysis of prosocial action. Soc. Psychol. Q. 1987, 50, 247-256. [CrossRef]

54. Riley, A.; Burke, P.J. Identities and self-verification in the small group. Soc. Psychol. Q. 1995, 58, 61-73. [CrossRef]

55. Bandura, A. Self-efficacy: Toward a unifying theory of behavior change. Psychol. Rev. 1977, 84, $191-215$. [CrossRef] [PubMed]

56. Tierney, P.T.; Farmer, S.M. Creative self-efficacy: Its potential antecedents and relationship to creative performance. Acad. Manag. J. 2002, 45, 1137-1148.

57. Bartimote-Aufflick, K.; Bridgeman, A.; Walker, R.; Sharma, M.; Smith, L. The study, evaluation, and improvement of university student self-efficacy. Stud. High. Educ. 2016, 41, 1918-1942. [CrossRef]

58. Yao, T.H.; Yu, C.P. Research on the relationship between mentor-peer support, research self-efficacy and graduate research creativity. Explor. High. Educ. 2019, 4, 46-53.

59. Bird, B.J. Implementing entrepreneurial ideas: The case for intention. Acad. Manag. Rev. 1988, 13, $442-453$. [CrossRef]

60. Choi, J.N. Individual and contextual predictors of creative performance: The mediating role of psychological processes. Creat. Res. J. 2004, 16, 187-199. [CrossRef]

61. Ajzen, I. From Intentions to Actions: A Theory of Planned Behavior; Springer: Berlin, Germany, 1985; pp. 11-39.

62. Emami, A.; Dimov, D. Degree of innovation and the entrepreneurs' intention to create value: A comparative study of experienced and novice entrepreneurs. Eurasian. Bus. Rev. 2016, 12, 1-22. [CrossRef] 
63. Arts, J.W.C.; Frambach, R.T.; Bijmolt, T.H.A. Generalizations on consumer in innovation adoption: A meta-analysis on drivers of intention and behavior. Int. J. Res. Mark. 2011, 28, 134-144. [CrossRef]

64. Taylor, S.; Todd, P.A. Understanding information technology usage: A test of competing models. Inf. Syst. Res. 1995, 6, 144-176. [CrossRef]

65. Ajzen, I.; Driver, B.L. Application of the theory of planned behavior to leisure choice. J. Leis. Res. 1992, 24, 207-224. [CrossRef]

66. Bateman, T.S.; Crant, J.M. The proactive component of organizational behavior: A measure and correlates. J. Organ. Behav. 1993, 14, 103-118. [CrossRef]

67. Crant, J.M. Proactive behavior in organizations. J. Manag. 2000, 26, 435-462. [CrossRef]

68. Seibiert, S.E.; Kraimer, M.L.; Crant, J.M. What do proactive people do? A longitudinal model linking proactive personality and career success. Pers. Psychol. 2001, 54, 845-874. [CrossRef]

69. Morrison, E.W. Newcomer information seeking: Exploring types, modes, sources and outcomes. Acad. Manag. J. 1993, 36, 557-559.

70. Fuller, B.; Marler, L.E. Chang driven by nature: A meta-analytic review of the proactive personality literature. J. Vocat. Behav. 2009, 75, 329-345. [CrossRef]

71. Belwalkar, B.B.; Tobacyk, J.J. Toward a tripartite model and measurement of proactive personality. J. Pers. Assess. 2018, 100, 529-538. [CrossRef]

72. Preacher, K.J.; Rucker, D.D.; Hayes, A.F. Addressing moderated mediation hypotheses: Theory, methods, and prescriptions. Multivar. Behav. Res. 2007, 42, 185-227. [CrossRef]

73. Wang, L. Dimension and scale development of implicit followership of university research team leaders-based on KAQ theory. Oper. Manag. 2020, in press.

74. Fishbein, M.; Ajzen, I. Belief, Attitude, Intention and Behavior: An Introduction to Theory and Research; Addison-Wesley: Boston, MA, USA, 1975; pp. 298-318.

75. Shang, J.Y.; Gan, Y.Q. The Influence of Proactive Personality on Career Decision-Making Self-Efficacy of College Graduates; Journal of Peking University (Natural Science Edition): Beijing, China, 2009; pp. 548-554.

76. Bentler, P.M. Comparative fit indexed in structural model. Psychol. Bull. 1990, 107, 238-246. [CrossRef]

77. Muthén, L.K.; Muthén, B.O. Mplus User's Guide (Version 6th); Muthén \& Muthén: Los Angeles, CA, USA, 2010.

78. Jöreskog, K.G. A general approach to confirmatory maximum likelihood factor analysis. Psychometrika 1969, 34, 183-202. [CrossRef]

79. Yuan, K.H.; Bentler, P.M. Three likelihood-based methods for mean and covariance structure analysis with nonnormal missing data. Soc. Methodol. 2000, 30, 165-200. [CrossRef]

80. Tucker, L.R.; Lewis, C. A reliability coefficient for maximum likelihood factor analysis. Psychometrika 1973, 38, 1-10. [CrossRef]

81. Steiger, J.H.; Lind, J.C. Statistically based tests for the number of common factors. Paper Presented at the Annual Meeting of the Psychometric Society, Iowa City, IA, USA, 30 May 1980.

82. Bentler, P.M. EQS Structural Equations Program Manual; Multivariate Software: Encino, CA, USA, 1995.

83. Hayes, A.F. An index and text of linear moderated mediation. Multivar. Behav. Res. 2015, 50, 1-22. [CrossRef] [PubMed]

84. Vignoli, M.; Depolo, M. Transfer of training process. When proactive personality matters? A three-wave investigation of proactive personality as a trigger of the transfer of training process. Pers. Individ. Differ 2019, 141, 62-67. [CrossRef]

85. Hua, J.; Zheng, L.; Zhang, G.L.; Fan, J.Y. Proactive personality and cross-cultural adjustment: A moderated mediation model. Int. J. Intercult. Relat. 2019, 72, 6-44. [CrossRef]

(C) 2020 by the authors. Licensee MDPI, Basel, Switzerland. This article is an open access article distributed under the terms and conditions of the Creative Commons Attribution (CC BY) license (http://creativecommons.org/licenses/by/4.0/). 